Effects on aspects of trainees' lives of shifts compatible with new deal. Figures are numbers (percentages) of respondents $(n=758)$

\begin{tabular}{lccc}
\hline Aspect of life & Better & Worse & Multinomial confidence interval for difference in proportions \\
\hline Teaching opportunities & $50(6 \cdot 6)$ & $503(66 \cdot 4)$ & $-0 \cdot 64$ to $-0.55^{\star}$ \\
Research opportunities & $137(18 \cdot 1)$ & $295(38 \cdot 9)$ & $-0 \cdot 25$ to $-0 \cdot 16^{\star}$ \\
Study time for examinations & $339(44 \cdot 7)$ & $173(22 \cdot 8)$ & $0 \cdot 16$ to $0 \cdot 27^{\star}$ \\
Fatigue while on call & $472(62 \cdot 7)$ & $96(12 \cdot 7)$ & $0 \cdot 44$ to $0.54^{\star}$ \\
Social and family life & $198(26 \cdot 1)$ & $397(52 \cdot 4)$ & -0.32 to $-0 \cdot 30^{\star}$ \\
Overall quality of life & $220(29 \cdot 0)$ & $309(40 \cdot 8)$ & -0.16 to $0.05^{\star}$ \\
\hline
\end{tabular}

$\star \mathbf{P}<0.05$.

departments had implemented shifts compatible with the new deal, 32 indicated that these had been rejected, mostly because of resistance by trainees (28 replies). Four hundred and fifty six respondents gave reasons for the non-implementation or rejection of the shifts, the two main reasons being "not enough trainees" (214) and "change resisted by trainees" (166).

Overall, 473 respondents did not think that the introduction of shifts compatible with the new deal would improve their training in anaesthesia. The table shows members' opinions on what effect the shifts would have on various aspects of their lives. Only 121 preferred to continue with or convert to a shift compatible with the new deal, while 451 wanted to base average hours on intensity of the workload as defined by the new deal but to allow the maximum length of the shift to be decided locally by trainees.

Significantly, only six of the 25 trainees at Glasgow Royal Infirmary thought that fatigue on call had improved and three thought that study opportunities had increased while they were working shifts compatible with the new deal.

These surveys suggest that, in anaesthesia, the clear withdrawal of restrictions on the maximum length of a shift from the new deal's guidelines would favour the uptake of flexible shiftwork without exacerbating fatigue on call. Shortages of staff may continue to impede the reduction of contracted and actual hours to the level commensurate with the intensity of the workload (64 hours a week) but should not prevent trainee anaesthetists from being contracted for the appropriate class (2) of additional duty hours. A report on the survey of the group of anaesthetists in training has been sent to the bodies responsible for negotiating and implementing the new deal. There is no reason to assume that these findings are exclusive to anaesthesia.

PETER MACKENZIE Group of Anaesthetists in Training Committee, Association of Anaesthetists of Great Britain and Ireland,

1 NHS Management Executive. Funior doctors. The new deal. London: NHSME, 1991.

\section{Anaesthetics training in the United States}

EDITOR,-In response to the report of the chief medical officer's working group, ${ }^{1}$ the Royal College of Anaesthetists published plans for a new structured training programme for the specialty. ${ }^{2}$ It will take six years to train as an anaesthetist. I am caught up in both the old and the new systems. I spent two years as a senior house officer and three as a registrar. I am currently employed for 18 months in the United States, in a teaching and research post. On my return I will have to complete a further two years as a senior registrar (the new term will be specialist. registrar). My anaesthetics training will have lasted more than eight years.

This contrasts greatly with anaesthetics training in the United States, where the training programme lasts three years, but "residents" (trainees) may then opt to do a further six month "fellowship" in a specialty. Three years after start- ing in the specialty they are considered to be fully trained and may begin practice as an "attending" (consultant). The discrepancy between our programmes means that most of the residents I am now supervising will be consultants before I am.

Training in the United States takes half the time that even the new structured training programme in the United Kingdom will take. The amount and quality of formal teaching are similar to those in the United Kingdom, but the supervision at work is vastly superior: trainees are supervised throughout their three year training. One attending is in charge of two residents for the day. Patients are seen preoperatively by both the resident and the attending. The attending rotates from one theatre to another, is always present at induction of anaesthesia, and is usually present at emergence from anaesthesia. Whenever necessary the resident will call the attending to assist (if he or she is not already present). This system provides a safe environment for trainees to practise their skills, as well as many opportunities for teaching and discussion. The level of supervision is the same throughout the nights and weekends and whether the case is an arthroscopy or open heart surgery. Confidence in the quality of the training is reflected in the fact that on completion of their residency it is not obligatory (although it is desirable) for residents to pass their "board" exams before they can practise independently.

This system results in confident and competent anaesthetists. This indicates that the quality of the learning experience rather than the length of the apprenticeship is the more important factor British trainees know that the length of training has more to do with providing a service than with gaining new skills, and this fact has been openly acknowledged. ${ }^{3}$ If the quality of the teaching and supervision is to be improved the numbers of staf will have to be increased so that the same level of neutral process. Indeed, the length of training will ultimately be determined by the amount of money that the government makes available.

GEOFFREY N MORRIS University of Virginia, Assistant professor in anaesthesiolog

Charlottesville,

USA

1 Department of Health. Hospital doctors: training for the future. The report of the working group on specialist medical training. London: DoH, 1993.

2 Royal College of Anaesthetists. Specialist training in anaesthesia supervision and assessment. London: RCA, 1994.

3 Norman J. Learning to teach anaesthesia. Royal College of Anaesthetists Newsletter 1995 Mar:1.

\section{Doctors are promoting expansion in non-consultant career grades}

EDITOR, - With the implementation of the Calman report and the restriction of junior doctors' working hours to 52 a week (plus four hours of educational time), the existing pattern of hospital staffing in the United Kingdom is clearly unsustainable without a large increase in the number of hospital doctors. All agree that increasing the service can be provided. This cannot be a cos number of junior doctors is out of the question (even though over 700 additional senior house officers have been appointed in the past year despite apparently tight controls). Achieving $A$ Balance envisaged that with the reduction in the availability of junior doctors the work would be carried out by increased numbers of consultants together with a small number of non-consultants (staff grade doctors and associate specialists), who for personal reasons were unable to progress to consultant status.

I now perceive an alliance between trusts, many consultants already in post, and some junior doctors (who hope to become consultants of the old style) promoting an unfettered expansion in these non-consultant career grades to do the medical work in hospitals, mainly at unsocial hours, that until now has been done by junior doctors. Those in the profession who are supporting this move are allowing the government, through the trusts, to staff hospitals with cheap labour; they will force many specialist trainees to accept posts in these grades with lower remuneration than if the profession insisted that such work must be carried out by doctors whose remuneration was equivalent to that for the current consultant grade, with an appropriate and realistic premium for work at unsocial hours.

To date most of the doctors appointed to the associate specialist grade and the staff grade have been aware of their personal difficulties in attaining full specialist training. If, however, we were to move to a scenario in which large numbers of nonconsultant doctors with poor pay and conditions had been frustrated in their realistic hopes of achieving at least the pay of the consultant grade, the United Kingdom might well be faced with large numbers of demoralised hospital doctors, some in middle age, who would be unlikely to be the most enthusiastic deliverers of efficient specialist care in our hospitals in the middle of the night, when illness can be at its most critical.

M J GOODMAN

Bury General Hospital,

Bury,

Bury,
Lancashire BL9 6PG

1 United Kingdom Health Departments. Hospital medical staffing: achieving a balance. Plan for action. London: HMSO, 1987.

\section{The changing role of hospital consultants}

EDITOR,-We agree with John Bailey that traditional working arrangements must be changed and that consultants should seize the initiative.' $\mathrm{He}$ suggests that a hierarchical management structure, as found in Sweden and other countries, should be adopted. In contrast, we believe that consultants should support the creation of management teams within a horizontal structure. ${ }^{2}$ Each team can develop expertise in a particular specialty and should provide flexibility for each member's skills to be applied for the benefit of the patients. The team consists of an appropriate skill mix of at least one consultant, clinical nurse specialists, assistant physicians, trainees, and secretarial staff. Continuity of care is provided by the multidisciplinary approach within the team and by staff who are introduced to the patient at the initial consultation and whom the patient sees consistently.

Within an institution each team acts as both a consumer and a supplier of services through its interactions with other teams. We believe that line managers should be facilitators rather than have subordinates. They can help to coordinate teams to provide cross cover and to mediate the allocation of resources within budgetary constraints. Facilitators could be elected by teams from their own members on a rotational basis to allow closer 
contact between those managing patients and those managing the institution. They would also interact with financial advisers and institutional service managers at board level.

There are some difficulties in implementing a horizontally managed, team based approach. For example, governments, institutions, and professional organisations would need to modify existing regulations ${ }^{3}$ and redefine their relations. Individuals must learn to value each other's contributions and be prepared to work in small groups, with some of the conflict and intimacy that that implies. ${ }^{4}$ This, however, allows more opportunities for consultants to implement their many skills. A consultant's professional responsibilities include the management of patients, education of trainees and colleagues, and research. Administration is also a major commitment and includes personal time management, continuing education, quality control (audit), the development of policies and guidelines, committee work, and participation in professional and political organisations. Consultants are more able to fulfil these essential tasks by working in a team with a flexible skill mix.

In summary, consultants' professional role is enhanced by the opportunity for initiative, task sharing, and delegation within a team with a mix of skills. This can reduce role conflict, ${ }^{5}$ decrease stress, foster morale, and improve the quality of patients' care.

$$
\begin{array}{rr}
\text { STEPHEN M SAGAR } & \text { HELEN RHYDDERCH } \\
\text { Consultant oncologist } & \text { Clinical nurse specialist in oncology } \\
\text { GLENN JONES } & \text { BARBARA THORSON }
\end{array}
$$

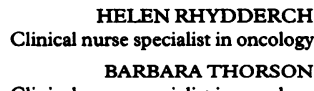

Consultant oncologist

Hamilton Regional Cancer Centre,

Hamilton,

Ontario L8V 5C2,

Canada

1 Bailey J. Rethinking consultants. Time for change in traditional working practices? $B M F$ 1995;310:788-90. (25 March.)

2 Denton DK. Horizontal management. Beyond total customer satisfaction. New York: Lexington, 1991.

3 Who is a surgeon ... [editorial]. Lancet 1995;345:663-5.

4 Sampson EE, Marthas M. Group process for the health professions. Albany, New York: Delmar, 1990.

5 Vachon MLS. Stress in oncologists. Canadian fournal of Oncology 1993;3:166-72.

\section{Emotions aroused by being on call}

\section{Need for anonymity condemns profession}

EDITOR,-The vivid thoughts about being on call described in a personal view will evoke deep feelings in many doctors. ${ }^{1}$ I am approaching my mid-40s and face yet another weekend on call. I know that some of these thoughts will occur to me, although they are now familiar and rather worn.

The author of the personal view, reasonably, remains anonymous. Surely this must be the greatest condemnation of our profession-that so many of us will strongly identify with the emotions expressed but feel shame either to admit to them or to listen to a colleague who has them.

West Bridgford, General practitioner

Nottingham NG2 7DA

1 Rites of passage of a medical career. $B M F$ 1995;310:1144. (29 April.)

\section{Australian doctors extract financial penalty for extra hours}

EDITOR,-I remember the resentment described by the young author writing about being on call'; I call it bitterness now. I live in Australia but was educated in Britain. I have ruminated for years on the need for doctors' internment. I have never believed that it is a better education to walk the dark corridors and prescribe paracetamol or, while disoriented, give an injection to the wrong patient Long ago, however, I realised that there was no political will for change in Britain. In fact, as a group, doctors are particularly well managed by the health authorities in Britain.

Now I live in Australia, working 40 hours a week in accident and emergency, with one week of nights in every seven, for $£ 10$ an hour. Overtime is paid at double the normal rate or more. If more than 16 hours are worked in a day the fatigue pay is paid at double time the next day and fatigue leave can be, and is, taken. The cost of staffing inhibit excessive hours. I do not believe that the patients have suffered.

I am told that this system came about because of the threat of industrial action. I believe that it can and should be achieved in Britain: doctors' families and patients deserve it.

G HAMILTON

Accident and Emergency

Southport Q4215,

Australia

1 Rites of passage of a medical career. BMF 1995;310:1144. (29 April.)

\section{BMA council's annual report}

\section{Is out of touch}

EDITOR,-Sometimes I wonder how in touch the powers that represent us really are. A paragraph in this year's annual report of the BMA's council states: "That this Meeting urges the Editor of the $B M F$ to seek the inclusion of the following details in all job advertisements [for junior hospital staff] carried in the BMF. . . (ii) number of UMTs payable."

We have been paid in additional duty hours since 1992 .

CHRISTOPHER L SHEEN Whipps Cross Hospital, London E11 1NR

1 BMA. Annual report of council 1994/95. London: BMA, 1995:67.

\section{BMA secretary's reply}

EDrTOR,-The BMA is aware that additional duty hours rather than units of medical time have been paid since 1992. The paragraph that Christopher $\mathbf{L}$ Sheen mentions refers to BMA policy made in 1990 , before the advent of additional duty hours.

$$
\text { E M ARMSTRONG }
$$

BMA,

Secretary

London WC1H 9JP

\section{Postgraduate training in Italy}

EDrTor,-We wish to add to the discussion about specialisation in Europe. In the past few years both the undergraduate and the postgraduate Italian medical curriculums have been reformed. Previously, no examinations had to be taken for entry to undergraduate courses and there were fairly relaxed entry examinations for the postgraduate curriculum; admissions have now been greatly restricted. In particular, postgraduate training changed dramatically with a reform in 1991 that was meant to bring Italian specialist training up to European standards. On average, the reform has reduced the yearly enrolment of postgraduate trainees by a factor of more than 10 . Trainees are now requested to attend the wards for at least 38 hours a week, have to be on the on call rota, and in principle have the same clinical responsibility as the most junior permanent staff-that is, "as- sistants," whose role is similar to that of the British senior house officers.

This reform is a great improvement, because previously postgraduate training consisted mainly of working from books and clinical practice was seen as optional. The new legislation and reforms, however, are only as good as the people who have to endorse them, and at present the reforms have not changed the attitude of trainers towards trainees. Thorough general teaching of practical skills and the subsequent acquisition of medica and surgical proficiency by all trainees are still a long way off in Italy. Most trainees do only menial jobs, such as clerking patients.

To act on this, in 1993 the Medical Association of European Union Specialists was set up. Members of the association comprise trainees enrolled since the 1991 reform. The association aims to be the Italian voice of specialists who have qualified in the European Union. It has over 4000 members and is working to improve training and trainees' conditions. Its second general meeting, on 1112 March 1995 in Rimini, was attended by Mrs I Reilly, who is secretary of the Advisory Committee on Medical Training of the European Commission; she will present the issues raised to the commission. We are keen to be contacted by other European trainees to establish a permanent means of sharing experiences throughout the European Union so that better training is achieved both in Italy and in the rest of Europe. We believe that improved medical and specialist training is essential both to improve the standard of medical care and to reduce the costs of health care throughout the world.

PAOLA ALBERTAZZ Researcher in obstetrics and gynaecology GIOVANNI GHERSI

President, Medical Association of European Union Specialists Ferrara University Hospital,

44100 Ferrara,

Italy

\section{Hospitals pay value added tax on drugs}

EDITOR,-I wonder how many doctors are unaware, as I was until recently, that hospital pharmacies pay value added tax on drugs and medicines. This comes out of the budgets of individual clinical directorates as part of their drugs bill, reducing the amount of money available for both inpatient and outpatient care. Community pharmacists can reclaim from Customs and Excise the value added tax that they have paid on drugs dispensed to patients presenting a prescription from their general practitioner, but hospital pharmacies cannot reclaim the tax.

This is not a new imposition, but I find it surprising and unacceptable in view of recent controversy about value added tax on domestic fuel, children's clothes, and books. Perhaps this anomaly should be considered further.

I ANNE TATT Consultant in genitourinary medicine Royal Liverpool University Hospital,

Liverpool L7 8XP

\section{Advice to author}

We prefer short letters that relate to a recently published article and we are unlikely to publish letters longer than 400 words and containing over five references. Letters may be shortened. Your letters should be typed with double spacing and include a word count. All authors need to sign the letter and provide one current appointment and address. We encourage you to declare any conflict of interest. Please enclose a stamped addressed envelope if you require an acknowledgment. 